\title{
Between Kinds and Properties: Bare Plurals across Languages
}

\author{
Ariel Cohen \\ Ben-Gurion University of the Negev \\ arikc@bgu.ac.il
}

\section{The Ambiguity of Bare Plurals}

It is well known that English sentences containing bare plurals (henceforth BPs) are ambiguous. Under one reading, they can be interpreted as a predication of some property directly of a kind, as in (1a), which says that the kind dog is extinct. Alternatively, they can express some characterizing property of instances of a kind, as in (1b), which says that, in general, individual dogs are intelligent. Yet a third reading is existential, as in (1c), which says that some dogs are barking outside right now.
(1) a. Dogs are extinct.
b. Dogs are intelligent.
c. Dogs are barking outside right now.

An important question to consider is the denotation of BPs in each one of these readings: is every reading associated with a different denotation of the BP? Or do BPs retain a uniform denotation, and the source of the ambiguity lies elsewhere? Or perhaps some combination of the above is correct, where BPs have the same denotation under two readings, but a different denotation under the third one?

The first two options appear to be the most elegant. Yet, in this paper I argue for the third option, on both empirical and theoretical grounds. The organization of this paper is as follows. In the following section I will present two influential theories of type-shifting, which make heavy use of type-shifting: Chierchia (1998) and Krifka (2004). Section 3 will focus on the differences between these two theories regarding the denotations of BPs in generic and existential sentences. In Section 4 I propose a an approach which I consider to be a synthesis of the best in Chierchia's and Krifka's theories. Section 5 turns to Italian in order to find support for the proposed theory, and putative counterexamples are discussed in Section 6. Section 7 is a brief conclusion.

I would like to thank Chris Barker, Gennaro Chierchia, and Louise McNally for helpful discussions. 


\section{Type-Shifting Accounts of English Bare Plurals}

\subsection{Points of Agreement}

Two influential theories of BPs (Chierchia 1998, Krifka 2004) employ type-shifting. While the two theories are different (and we will get to the differences in a moment), they share many points of agreement, of which I will list six.

The first three points of agreement have to do with the nature of typeshifting:

1. Type-Shifting Operators. Chierchia and Krifka agree on the basic inventory of type-shifting operators. In particular, the following operators will be relevant to the current paper.

One is the existential type-shift, whose definition goes back to Partee (1987):

$$
\exists P=\lambda Q \exists x(P(x) \wedge Q(x))
$$

Another is $l$, which corresponds to the definite determiner in English:

$$
\imath P=\text { the maximal element in } P \text { (where defined) }
$$

This definition has the effect that if $P$ is a singular property, say DOG, $\imath P$ picks the unique element that satisfies it (if there is such an element), i.e. the unique dog in context. And if $P$ is a plural property, e.g. DOGS, $\imath P$ is the largest plurality of $P$, i.e. the plurality of all dogs.

Two additional operators are the $\cap$ and the $\cup$ operators, which turn a property into a kind and vice versa, respectively. Chierchia and Krifka treat the kind $\cap P$ as a function that produces, for each world, the maximal plurality of $P \mathrm{~s}$ in that world. Formally, the $\cap$ operator is defined as follows:

$$
\cap_{P}=\lambda s i P_{s} \text { (where defined). }{ }^{1}
$$

The operator that turns a kind into a property is the $U$ operator. It returns a function that, for each world, returns the property of being a part of the plurality that comprises all the atomic elements of the kind. Formally:

$$
\cup_{k}=\lambda s . \lambda x . x \leq k_{s}
$$

Thus, for example, if $d$ is the kind $d o g$, then $\cup d$ is the property of being an element of the maximal plurality of dogs, i.e. the property of being a dog.

2. The last resort principle. Both Chierchia and Krifka follow Partee and Rooth (1983) in assuming that type-shifting does not occur freely, but only if it is necessitated by type mismatch.

3. The blocking principle. Type-shifting is blocked if a language can achieve the same effect by overt means. That is to say, in language $L$ there is no type-shifting operator $\tau$ if $L$ contains an overt operator $D$ s.t. for every argument $X, D(x)=\tau(X)$.

\footnotetext{
${ }^{1}$ Not every property can be turned into a kind, hence ${ }^{\cap} P$ is not defined for every $P$; but I will not get here into the conditions that make $\cap P$ well defined.
} 
Three additional points of agreement have to do with the nature of BPs:

4. BPs are basically properties. That is to say, their initial denotation, before typeshifting, is that of a property. The $\cap$ operator can apply to shift this property to a kind. Indeed, this is what happens in cases of direct kind predication, as in (1a). So, according to both Chierchia and Krifka, BPs in direct kind predication (after type-shifting) denote kinds.

5. The Generic Quantifier. Chierchia and Krifka share the widely held assumption that characterizing generic readings involve a phonologically null generic quantifier. The precise truth conditions of this quantifier do not concern us here, but its meaning can be glossed, somewhat inaccurately, as "in general". 2

6. Existential readings. Existential readings of BPs are provided by type shifting. ${ }^{3}$ It is well established that existential BPs are restricted to narrow scope only. Thus, (6a) can mean (6b) but not (6c).

(6) a. I didn't meet beautiful girls

b. It is false that there exist beautiful girls whom I met.

c. There exist beautiful girls whom I didn't meet.

Chierchia and Krifka explain this fact by assuming that type shifting is local. As Krifka puts it: "if we follow Chierchia and assume that type shifting occurs as late, or as locally, as possible,... type shifting predicts that bare NPs have narrow scope."

The last point, regarding the existential interpretation, requires some elaboration. I turn to it in the next two subsections.

\subsection{Type-Shifting and Scope}

As we have seen, Chierchia and Krifka account for the narrow scope of BPs by appealing to the locality of type-shifting. The question arises whether locality is only restricted to those type-shifting operators that result in the existential readings of BPs (as Chierchia implies), or applies to type-shifting in general.

In order for this account of BPs to be convincing, the locality of typeshifting ought to be a general phenomenon, not restricted only to BPs. And this does, indeed, appear to be the case; there is evidence that all type-shifting is local.

Consider negation, for example. Usually, it is scopally ambiguous: (7a) can mean either $(7 b)$ or $(7 c)$.

(7) a. John didn't buy a new coat.

b. John didn't buy any new coat.

c. There is a new coat that John didn't buy.

\footnotetext{
${ }^{2}$ See Cohen (1999) for my view on the meaning of the generic quantifier.

${ }^{3}$ Chierchia and Krifka do not, however, agree on the precise nature of the type-shifting operator involved: for Krifka, this is $\exists$, whereas for Chierchia it is a special operation of Derived Kind Predication (DKP). This difference, however, need not concern us here.
} 
But note what happens when we conjoin didn't buy with an intensional verb that is read de dicto: (8a) can only mean (8b); it does not get the reading paraphrased by $(8 \mathrm{c}){ }^{4}$

a. John needed but didn't buy a new coat.

b. John needed a new coat but didn't buy any new coat.

c. John needed a new coat but there is a new coat that John didn't buy. Why?

In the case of $8 \mathrm{a}$, then, negation is not ambiguous: it must get wide scope.

The reason has to with the fact that buy is shifted to the type of an intensional verb if conjoined with need (Partee and Rooth 1983):

$$
\operatorname{SHIFT}(\mathbf{b u y})=\lambda Q \cdot \lambda x \cdot Q(\lambda y \cdot \mathbf{b u y}(x, y))
$$

Now, we can shift the verb, and then negate the result: $\neg \operatorname{SHIFT(buy).~Then~we~}$ get:

$$
\neg \exists x(\operatorname{new}-\operatorname{coat}(x) \wedge \operatorname{buy}(\mathbf{j}, x))
$$

However, apparently we cannot negate the verb first and then type-shift, i.e. we cannot have SHIFT( $\neg$ buy). If we did, we would get:

$$
* \exists x(\operatorname{new}-\operatorname{coat}(x) \wedge \neg \operatorname{buy}(\mathbf{j}, x))
$$

But this reading is not available for (8a).

Hence, there is independent evidence that, in general, type-shifting is local. ${ }^{5}$

\subsection{Existential Readings and Blocking}

Why isn't the existential type-shifting of BPs blocked by the plural existential determiner some? In other words, since English has overt means to provide existential interpretations of plurals, why doesn't this fact block the application of type-shifting to produce the same means?

Chierchia and Krifka are aware of this difficulty, and they suggest that some contributes more information than simply an existential quantifier: specifically, that some introduces a choice function. Hence, the interpretations of some dogs and the existential interpretation of the BP dogs are not the same, and consequently the former does not block the latter.

Some evidence that this is what some does, and that it does not act simply as a determiner (unlike the singular $a / a n$ ), comes from the fact that it cannot introduce a variable to be bound by an adverbial quantifier. Thus, while (12a) means (roughly) that most dogs are intelligent, (12b) and (12c) cannot be so understood; they can only get the bizarre interpretation that there exists some dog (or dogs) whose intelligence keeps changing as time goes by, but is usually high.

\footnotetext{
${ }^{4}$ Of course, (8a) can also be read de re, as saying that there is a new coat that John needed but didn't buy; but this reading does not involve type-shifting, and does not concern us here.

${ }^{5} \mathrm{I}$ am not sure why that is so; one possible speculation is that type shifting is a costly operation, so we prefer to shift as little as possible.
} 
(12) a. A dog is usually intelligent.

b. *Some dog is usually intelligent.

c. *Some dogs are usually intelligent.

Thus, the singular determiner $a$ blocks the existential interpretation of bare singulars in English, while the plural some does not block the existential interpretation of BPs.

It appears to be possible to generalize this explanation across languages. Italian, for example, has no plural determiner either, but instead uses the bare partitive dei (Chierchia 1998).

$\begin{array}{llll}\begin{array}{l}\text { Dei } \\ \text { of-the }\end{array} & \text { ragazzi } & \text { sono arrivati } & \text { in ritardo. } \\ \text { arrived } & \text { late }\end{array}$

'(Some) boys arrived late'

Being a partitive, the meaning of dei is not simply that of an existential, hence it does not block the existential reading of BPs, as we will see in Section 5.2 below.

In Spanish too, existential readings of BPs are possible:

(14) Marta compró naranjas (McNally 2004)

'Marta bought oranges'

Unlike Italian, Spanish does have a plural existential determiner, unos/unas. However, it behaves more like English some than like an indefinite singular. For example, it apparently cannot restrict the domain of an adverbial quantifier (Louise McNally, pc) and there are reasons to believe that, like some, it denotes a choice function (Palma to appear). Hence, the existence of unos/unas in Spanish does not block the existential interpretation of the BP.

The situation in French is different: in this language, BPs are not allowed. ${ }^{6}$ Instead, French uses the indefinite article des.

So, we could suggest that the existential reading of BPs is blocked by this article. $^{7}$ One potential problem with this view is that it does not appear to be possible to bind des NPs by an adverb of quantification. The following examples are from Dobrovie-Sorin (to appear):

a. *Des enfants marchent rarement avant 10 mois.

'Children rarely walk before the age of 10 months'

b. *Des Indiens meurent en général jeunes.

'Indians usually die young'

Thus, it looks that, just like some in English, des is not really a determiner, hence it should not block existential type-shifting. However, the impression created by the sentences in (15) may be misleading. Dobrovie-Sorin (to appear) points

\footnotetext{
${ }^{6}$ Except for a few special circumstances, such as predicative structures, coordination, and enumerations.

${ }^{7}$ And, incidentally, the generic reading is blocked by the definite article, just like in Italian, see Section 5 .
} 
out that while des NPs cannot form the restriction of quantification over singular individuals, they do allow quantification over plural individuals:

a. Des pays limitrophes ont souvent des rapports difficiles.

'Neighboring countries frequently have difficult relations'

b. Des amis intimes se critiquent toujours.

'Intimate friends always criticize each other'

Sentence (16a) does not quantify over individual countries, but over groups of neighboring countries; and (16b) only makes sense if quantifying over groups of friends. In such cases, des NPs can, in fact, restrict the domain of a quantificational adverb. Hence, des is a real determiner, and is, therefore, able to block the existential type-shift of BPs in French.

\section{Between Kinds and Properties}

\subsection{An Additional Point of Agreement}

Chierchia and Krifka agree on one other point: in both characterizing and existential readings, the denotation of BPs is the same, though it may later be type-shifted to an existentially or generically quantified variable. However, they disagree on what the denotation of BPs is.

According to Chierchia, BPs denote kinds. For example, the BP dogs denotes the kind ${ }^{\cap}$ DOGS, which is a function from each world to the maximal plurality of dogs in that world: $\lambda s i \mathbf{D O G S}_{s}$.

In contrast, for Krifka BPs are simply (plural) properties. Thus, the meaning of the BP dogs is the property DOGS. Let us look briefly at some of the arguments that Chierchia and Krifka present for their respective views.

\subsection{Two Arguments for Kinds}

\subsubsection{Bare Singulars}

Bare singular count nouns are not allowed in either direct kind predication, characterizing, or existential sentences:

(17) a. ${ }^{*}$ Dog is extinct.

b. *Dog is intelligent.

c. *Dog is barking.

According to Chierchia, all these cases require type-shifting to kinds. According to his theory, this is possible only with cumulative (plural and mass) properties, but not with singular properties. Hence, the unacceptability of the sentences in (17) is used to argue that the acceptable corresponding sentences with BPs involve reference to kinds. 
This argument has a lot of merit, and I think it succeeds with both types of generic reading: direct kind predication and characterizing generics.

However, with the existential reading there is an alternative, simpler explanation: the existential reading of bare singulars is blocked by the indefinite existential determiner, a/an.

This explanation accounts for the fact, noted by Chierchia, that there are no languages that allow bare singulars but not bare plurals. The reason is that there are no languages with a plural indefinite determiner but no singular indefinite determiner.

\subsubsection{Scopally Ambiguous BPS}

As we have seen above, existential BPs are restricted to narrow scope only. But Chierchia, following Carlson (1977), claims that this is the case only if the BPs may refer to kinds. BPs that cannot be interpreted as kind denoting are ambiguous. Thus, for example, the BP parts of that machine cannot plausibly be seen as denoting a kind. Hence, (18a) is ambiguous, and can mean either (18b) or (18c).

a. John didn't see parts of that machine.

b. John didn't see any parts of that machine.

c. There are parts of that machine that John didn't see.

Again, there is an alternative explanation that does not require kind reference. It may well be the case that BPs like parts of that machine cannot denote kinds. However, this is not what allows them to receive wide scope. This comes about because they can get a specific interpretation.

The problematic BPs mentioned by Chierchia are boys sitting here, people in the next room, and parts of that machine. These BPs plausibly do not denote kinds. But they also, intuitively, talk about a specific group of individuals, restricted in time and space. So, in general, it is not easy to distinguish which characteristic (the inability to denote kinds or the possibility of a specific interpretation) is responsible for the scopally ambiguous reading.

However, consider this example from Geurts (to appear):

(19) Several students reported that they had been harassed by professors wearing false beards and pink gowns.

This sentence certainly has a reading, probably the preferred reading, where the same professors harassed all the students. Clearly, it is possible to conceive of a specific group of professors wearing false beards and pink gowns. But does this BP fail to denote a kind? Arguably, we can talk about the kind professors wearing false beards and pink gowns, as in:

(20) Professors wearing false beards and pink gowns grow more numerous as one gets closer to the area where the alien virus was released.

Hence, it appears that what is crucial about such examples is, indeed, specificity, and not the inability to denote kinds. 


\subsection{An Argument for Properties}

Krifka agrees that in cases of direct kind predication, the BP denotes a kind, after an application of the $\cap$ type-shifting operator. With characterizing and existential sentences, however, he argues that the type-shift from properties to kinds is not motivated by type mismatch, hence, by the last resort principle, it shouldn't occur. Therefore, Krifka concludes, the BPs in such sentences remain property-denoting, and are not shifted to kinds.

I believe this argument succeeds with the existential reading. However, type-shifting is motivated in the case of characterizing generics, for reasons of information structure.

I take the view that the topic is what the sentence is about (Reinhart 1981, Erteschik-Shir 1997, and many others). From this, two properties of topics follow. One is that topics are obligatory-every predicative sentence must have a topic. ${ }^{8}$ Another is that topics must be specific: they must denote individuals (singular, plural, kinds, or whatever).

As both Chierchia and Krifka (and many others) agree, the generic quantifier is phonologically null. The full implications of this fact, however, are not always appreciated. If the generic quantifier is phonologically null, this means that it is not originally "there", in the sentence. Hence, the "initial" logical form of a generic like (21) is predicative, not quantificational.

Dogs are intelligent.

Such a sentence must therefore have a topic. Properties are not specific, hence they cannot serve as topics. In contrast, kinds are specific. Hence, the property DOGS is type-shifted to the kind ${ }^{\cap}$ DOGS, so that the initial logical form of $(21)$ is:

\section{intelligent $(\cap$ DOGS $)$.}

Only at this stage may the generic quantifier be introduced, and the kind type-shifted back to a property. The resulting logical form is:

$$
\operatorname{gen}_{x}[\cup \cap \operatorname{DOGS}(x)][\operatorname{intelligent}(x)] .
$$

Crucially, the topic requirement had to be satisfied already at the predicational stage, hence the motivation for the type-shift. Thus, the application of the $\cap$ type-shifting operator to BPs in characterizing generics is motivated.

\footnotetext{
${ }^{8} \mathrm{cf}$. Krifka (2004): "As a general rule of discourse coherence, every sentence must have a topic" (p. 129).
} 


\section{A Synthesis}

\subsection{The Theory}

Let us take stock. The arguments for kinds appear to succeed only for characterizing readings (and, of course, direct kind predication), and the argument for propertiesonly for existential readings.

This situation calls for a synthesis of the views of Chierchia and Krifka. I suggest such a synthesis: I accept their six points of agreement, but, following Cohen and Erteschik-Shir (2002, cf. Van Geenhoven 1996, McNally 1998, DobrovieSorin and Laca 1996, Doron 2003), I suggest that characterizing BPs, like Chierchia claims, denote kinds, but existential BPs, like Krifka argues, denote properties. Thus, the BP dogs in (24a) denotes the kind ${ }^{\cap}$ DOGS $=\lambda s$ l DOGS $s$, while in (24b) it denotes the property DOGS. ${ }^{9}$

a. Dogs are intelligent.

b. John saw dogs.

The initial logical form of (24a) is:

intelligent(DOGS)

This creates a type mismatch, since the predicate intelligent requires an individual. We cannot "wait" until the eventual introduction of the generic quantifier to resolve this mismatch, since this is a predicative sentence, hence requires a topic already at the predicative stage. Therefore, the BP must be specific, hence it is type-shifted to the kind ${ }^{\cap}$ DOGS, and we get:

\section{intelligent $\left({ }^{\cap}\right.$ DOGS $)$}

This logical form is semantically well formed, but pragmatically odd: it is not the kind ${ }^{\cap}$ DOGS that is intelligent; only individual dogs can be intelligent. Hence, the generic quantifier is introduced, ${ }^{10}$ resulting in:

$$
\operatorname{gen}_{x}[\cup \cap \operatorname{DOGS}(x)][\operatorname{intelligent}(x)] .
$$

The existential reading is generated by the application of the $\exists$ operator. The initial logical form of (24b) would be:

$\operatorname{see}(\mathbf{j}$, DOGS $)$.

This causes a type mismatch, because the second argument of see ought to be an individual, and not a property. The mismatch is resolved by type-shifting: we apply $\exists$ to the property $\lambda x \operatorname{see}(\mathbf{j}, x)$, and, as desired, we get:

$$
\text { (29) } \exists x(\mathbf{D O G S}(x) \wedge \operatorname{see}(\mathbf{j}, \mathbf{D O G S}(x))
$$

\footnotetext{
${ }^{9}$ I will not discuss here my view on the reasons why the BP is interpreted generically in (24a) but existentially in (24b); the interested reader is referred to Cohen and Erteschik-Shir (2002).

${ }^{10} \mathrm{I}$ believe the mechanism responsible for this introduction is pragmatic in nature, and is similar to Nunberg's (1995) predicate transfer, but I will not pursue the matter further here.
} 
If we assume that type-shifting occurs as locally as possible, the existential interpretation receives narrow scope only. For example:

(30) John didn't see dogs.

The initial logical form of (30) is:

$\neg \operatorname{see}(\mathbf{j}, \operatorname{dogs})$.

If type-shifting applies locally, we first resolve see(j, DOGS), as before. Only then do we apply negation to the result, to get:

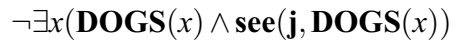

\subsection{The Data}

How do we decide the matter empirically? How can we determine, for each of the two relevant interpretations of a BP (existential and characterizing) whether the BP in question denotes a kind or a property?

Crucial pieces of evidence would be sentences where one occurrence of a $\mathrm{BP}$ is interpreted in more than one way. For example:

(33) Dodos lived in Mauritius and (they) became extinct in the 18th century. (after Heyer 1990).

The VP in this sentence consists of two conjoined predicates. The first predicate, lived in Mauritius, forces the BP to receive a characterizing reading. The second predicate, became extinct in the 18th century, forces it to be interpreted as direct kind predication. The fact that the sentence is good shows that in both cases, the BP denotes the same object. Hence, the BP must denote a kind in a characterizing generic as well as in sentences of direct kind predication.

Another crucial example is the following:

(34) ??Dogs are man's best friend and (they) are barking outside right now (Schubert and Pelletier 1987).

Again, we have a conjunction of two predicates. The first forces a generic interpretation of the BP, while the second forces an existential reading. The fact that this sentence is bad shows that the BP denotes different objects in each of the readings: if it denotes a kind in generic sentences, it must denote a property in existential ones.

If these judgments are granted, the theory presented here is confirmed empirically. However, it turns out that judgments are not so clear. As a matter of fact, Schubert and Pelletier (1987) present sentence (34) as an example of a good sentence, and use it to argue that existential BPs do denote kinds.

We must, therefore, look elsewhere for data to resolve the matter. A good place to look would be a language where BPs cannot denote kinds. Then, if in this language BPs get a characterizing reading, we would know that reference to kinds is not necessary for such readings; otherwise, we will conclude that it is. And the same goes for the existential reading. In the next section I will argue that Italian is precisely such a language. 


\section{Italian Bare Plurals}

\subsection{Direct Kind Predication}

Chierchia argues that direct kind predication is possible in Italian. His best examples are the following:

a. Qui, ragazze in minigonna sono rare.

'Here, girls in miniskirt are rare'

b. Dopo il disastro nucleare, purtroppo, cani con difetti congeniti sono molto comuni.

'After the nuclear disaster, unfortunately, dogs with birth defects are very common'

However, these examples are not entirely convincing, since rare 'rare' and comuni 'common' are arguably better analyzed as quantificational predicates than as kind predicates (Krifka et al. 1995). When we test the claim with predicates that unequivocally require kinds, we find that BPs are impossible (Longobardi 2001):

a. *Elefanti di colore bianco sono estinti.

'White-colored elephants have become extinct'

b. *Elefanti di colore bianco diventano sempre più grandi man mano che si va a nord

'White-colored elephants grow larger as one drives north'

c. *Elefanti di colore bianco sono così chiamati per la pigmentazione della loro pelle

'White-colored elephants are so-called because of the pigmentation of their skin'

We can therefore conclude that direct kind predication is not possible in Italian. ${ }^{11}$

What is the cause of this difference between Italian and English? Why can't BPs denote kinds in Italian? Following Dayal (2004b), I assume that in Italian, the definite determiner is ambiguous. Under one reading, it is like in English, denoting uniqueness (or, rather, maximality). Formally, the $N P$ is translated as $\imath P$, where $P$ is the denotation of the NP.

The second reading is, in a sense, an "intensional version" of the first: $\lambda_{s} \imath P_{s}$. This is a function from a world to the maximal plurality of $P \mathrm{~s}$ in that world. But note that this second reading of the definite determiner is precisely Chierchia's $\cap$ operator.

Indeed, Italian allows overt type-shifting of BPs to kinds, through the definite determiner:

(37) Gli elefanti di colore bianco sono estinti (Longobardi 2001)

'The white-colored elephants have become extinct'

\footnotetext{
${ }^{11}$ See also Dayal (2004a), Robinson (2005).
} 
By the blocking principle, if there is an overt determine that shifts a property to a kind, such type-shifting cannot apply covertly. Hence, $\cap$ cannot apply to Italian BPs, and therefore they cannot denote kinds.

\subsection{Existential Readings}

It is uncontroversial that Italian BPs allow existential readings. Moreover, just like in English, these readings are restricted to narrow scope only. Thus, (38) can only mean that it is false that there exist beautiful girls whom I met. It cannot get the interpretation where there exist beautiful girls whom I didn't meet.

(38) Non ho conosciuto belle ragazze

'(I) didn't meet beautiful girls'

Since BPs in Italian cannot refer to kinds, yet they do get existential readings, this is strong evidence that the existential interpretation does not require kind reference. This is explained if, as with Krifka and the current proposal, existential BPs denote properties. ${ }^{12}$

\subsection{Characterizing Generics}

Characterizing generic BPs are bad in Italian:

a. *Linguisti sono bravi (Chierchia 1998)

'Linguists are clever'

b. ??Cani da guardia di grosse dimensioni sono più pelosi/neri (Longobardi 2001)

'Watchdogs of large size are hairier/blacker'

Again, since Italian BPs cannot denote kinds, this provides evidence for the view that characterizing readings do require kind reference. This is compatible with Chierchia and the current proposal.

\subsection{And Therefore...}

So, in accordance with the proposed synthesis: characterizing, but not existential readings of BPs, require reference to kinds.

It would seem that this is an appropriate point to finish the paper, and declare the debate settled. However, there is a fly in the ointment.

Despite the fact that Italian BPs do not denote kinds, characterizing readings of BPs do appear to be possible in some cases:

\footnotetext{
${ }^{12}$ See also McNally (2004) for arguments that in Spanish, existential BPs denote properties too.
} 
(40) Cani da guardia di grosse dimensioni sono più efficienti/aggressivi (Longobardi 2001).

'Watchdogs of large size are more efficient/aggressive.'

Now, not all speakers of Italian agree that (40) is good; but quite a few do. Hence, we cannot ignore such examples, and need to provide some principled explanation for them.

Let us first get one red herring out of the way. The subject of (40) is rather "heavy"; could this be the reason why the sentence is good?

The answer is no. The heaviness requirements for subjects is not related to the possibility of a characterizing interpretation. First, we have already seen, with sentence (39b), an example of a sentence with a heavy subject BPs, that cannot get a generic interpretation nonetheless. Second, the heaviness requirement of Italian subject BPs applies even when they are interpreted existentially. For example, Chierchia points out that the sentences in (41) are bad; but when the subject becomes heavy, as in (42), the sentences become considerably better.
a.
*Studenti
hanno
telefonato.
students
have
phoned
*Hanno
have
telefonato
studenti.
students

'Students have phoned'
$\begin{array}{lllll}\text { Studenti } & \text { e colleghi } & \text { hanno telefonato. } \\ \text { students and colleagues have } & \text { phoned }\end{array}$

'Students and colleagues have phoned'

$\begin{array}{lllll}\text { b. Hanno telefonato studenti che volevano } & \text { sapere } \\ \text { have } & \text { phoned } & \text { students } & \begin{array}{l}\text { che } \\ \text { that }\end{array} \text { want } & \text { to find out }\end{array}$
la data dell'esame
the date of the exam

'Students who want to find out the date of the exam have phoned'

I am not aware of a completely satisfactory explanation of the heaviness requirements of subject BPs; but whatever the reason is, it is clear that this requirement is orthogonal to the generic interpretation of the BP.

How, then, can we explain sentences like (40)? The way to do so, I suggest, is to look at an additional use of BPs.

\section{Rules and Regulations}

In English, a BP can be used in a characterizing generic, i.e. it can be interpreted as making a descriptive generalization. But it can also also make a statement that some rule or regulation is in effect (Cohen 2001, cf. Carlson 1995, Greenberg 2003).

Take, for example, sentence (43), from de Swart (1996). 
Police officers do not behave like that in an emergency situation.

This sentence can make a statement about how police officers behave (or, rather, fail to behave) in emergency situations. It could, for example, be said by a reporter who is writing a piece about the police force.

But (43) also has another use. It could, for instance, be uttered by the chief of police, who is expressing outrage at the way the officers behaved in some incident. Under this use, the speaker does not describe the way police officers do actually behave, but rather how they ought to behave: the speaker describes some rule or regulation that police officers ought to abide by.

An important type of the rule-or-regulation use is one that can be interpreted as a trigger for some specific action. For example, the most plausible interpretation of (44) is the rule-or-regulation reading: because a certain norm exists, a certain action ought to be triggered.

(44) Police officers do not behave like that in an emergency situation, therefore stop that immediately!

Some authors believe that rule-or-regulation sentences are characterizing generics. However, there is evidence that this is not the case; and that in such sentences the BP denotes a property (like it does under the existential reading) and not a kind (like in a characterizing generic).

One piece of evidence involves indefinite singulars. Indefinite singulars may receive the action-trigger reading, even when they can't get a descriptive, characterizing reading. For example, take the following sentence, from Burton-Roberts (1977):

A gentleman opens doors for ladies.

Burton-Roberts (1977) note that (45) could be used to get the hearer to open doors for ladies, hence it can be used as an action trigger. It can also be read as a definition of what a gentleman is - a definition is another type or a rule or regulation. Crucially, however, (45) cannot be interpreted as a generalization about the observed behavior of gentlemen. If the rule-or-regulation is just one use of the characterizing reading, how can (45) get the former reading if it can't get the latter?

Another piece of evidence comes from action triggers in French. As mentioned above, in this language BPs are almost never allowed. Generic readings (both direct kind predication and characterizing generics) are indicated with the definite determiner les. Existential readings are indicated with the indefinite determiner des.

Interestingly, rules-or-regulation sentences are expressed with the indefinite determiner, not the definite determiner (Carlier 1989, as reported by de Swart 1996). Thus, a reporter writing about the police force would say (46a), whereas the chief of police, chastising some officers, would say (46b).

(46) a. Les agents de police ne se comportent pas ainsi dans une situation d'alarme. 'DEF-PL police officers do not behave like that in an emergency situation.' 
b. Des agents de police ne se comportent pas ainsi dans une situation d'alarme. 'INDEF-PL police officers do not behave like that in an emergency situation.'

So, rule-or-regulation sentences are indicated with the indefinite determiner, which is used for the existential reading, rather than the definite determiner, which is used for the generic reading.

I would like to make the following claim: what appear to be good characterizing generics in Italian are, in fact, rule-or-regulation sentences. Specifically, they are action triggers. Let me exemplify this claim with some minimal pairs from Longobardi (2001):

a. Cani da guardia di grosse dimensioni sono più efficienti/aggressivi (perquesto evitare Fido!)

'Watchdogs of large size are more efficient/aggressive (therefore avoid Fido!)'

b. ??Cani da guardia di grosse dimensioni sono più pelosi/neri (perquesto... ???)

'Watchdogs of large size are hairier/blacker (therefore... ???)'

(48) a. Stati di grandi dimensioni sono pericolosi (perquesto attaccateli!)

'States of large size are dangerous (therefore attack them!)'

b. ??Stati di grandi dimensioni sono prosperi (perquesto... ???)

'States of large size are prosperous (therefore...???)'

(49) a. Uccelli di zone paludose sono ghiotti di insetti (perquesto date a Tweety degli insetti!).

'Birds from marshy areas are greedy for insects (therefore feed Tweety some insects!)'

b. ??Uccelli di zone paludose sono scuri/intelligenti (perquesto... ???)

'Birds from marshy areas are dark/intelligent (therefore. . . ???)'

Sentence (47a) is good, because the efficiency or aggressiveness of watchdogs can be readily interpreted as triggering some specific actions, probably avoiding them. However, it is not so clear what action is triggered by the hairiness of watchdogs or their color, hence (47b) is not so good.

Similarly, (48a) is fine, because if a state is dangerous, some specific courses of action can be readily triggered. But if a state is prosperous, no course of action immediately suggests itself. And if a bird likes insects, the obvious action is to feed it; but if it is dark or intelligent, how would this affect our actions? ${ }^{13}$

Hence, what appears to be a characterizing BP in Italian is actually the action-triggering reading. Since under this reading the BP denotes a property rather than a kind, such examples do not constitute counterexamples to the theory developed here, according to which kind reference is necessary for characterizing generics.

\footnotetext{
${ }^{13}$ Longobardi (2001) notes that the good sentence are "somewhat more eventive" than the bad ones. This intuition is quite compatible with the idea that the good sentences are action triggers.
} 


\section{Conclusion}

The theory proposed here provides a uniform account of the similarities and differences in the behavior of BPs in two languages, English and Italian. In both of these languages, BPs originally denote properties.

These properties can be type-shifted by $\exists$ to receive existential readings; since type-shifting is local, these readings receive narrow scope only.

Alternatively, these properties can be interpreted as being a part of a rule or a regulation; in this case we get what looks like a characterizing generic, but, in fact, is not.

In English, there is a third option: the BP can be type-shifted by $\cap$ to a kind, to receive a generic reading: either direct kind predication or a characterizing generic. In Italian, this option is disallowed by the blocking principle: the overt definite determiner can do the same job.

Hence, in both languages, and perhaps universally, BPs are properties subject to constrained type-shifting.

\section{References}

Burton-Roberts, Noel: 1977, 'Generic Sentences and Analyticity', Studies in Language 1, 155-196.

Carlier, Anne: 1989, 'Généricité du syntagme nominal sujet et modalités', Travaux de Linguistique 19, 33-56.

Carlson, Greg: 1977, Reference to Kinds in English, Doctoral Dissertation, University of Massachusetts at Amherst. Also published 1980, New York: Garland.

Carlson, Greg: 1995, 'Truth-Conditions of Generic Sentences: Two Contrasting Views', in Carlson and Pelletier (1995), 224-237.

Carlson, Greg and Francis J. Pelletier (eds.): 1995, The Generic Book. University of Chicago Press, Chicago.

Chierchia, Gennaro: 1998, 'Reference to Kinds across Languages', Natural Language Semantics 6, 339-405.

Cohen, Ariel: 1999, 'Generics, Frequency Adverbs and Probability', Linguistics and Philosophy 22, 221-253.

Cohen, Ariel: 2001, 'On the Generic Use of Indefinite Singulars', Journal of Semantics 18, 183-209.

Cohen, Ariel and Nomi Erteschik-Shir: 2002, 'Topic, Focus and the Interpretation of Bare Plurals', Natural Language Semantics 10, 125-165.

Dayal, Veneeta: 2004a, 'Licensing by Modification'. ms., Rutgers.

Dayal, Veneeta: 2004b, 'Number Marking and (In)definiteness in Kind Terms', Linguistics and Philosophy 27, 393-450.

Dobrovie-Sorin, Carmen: to appear, 'Generic Plural Indefinites and (In)direct Binding', in F. Corblin and H. de Swart (eds.), A Handbook of French Semantics. CSLI, Stanford. 
Dobrovie-Sorin, Carmen and Brenda Laca: 1996, 'Generic Bare NPs'. Unpublished manuscript.

Doron, Edit: 2003, 'Bare Singular Reference to Kinds', in Proceedings of SALT XIII. Cornell Working Papers in Linguistics.

Erteschik-Shir, Nomi: 1997, The Dynamics of Focus Structure. Cambridge University Press, Cambridge.

Geurts, Bart: to appear, 'Specific Indefinites, Presupposition, and Scope', in R. Bäuerle, U. Reyle, and T. E. Zimmermann (eds.), Presuppositions and Discourse. Elsevier, Oxford.

Greenberg, Yael: 2003, Manifestations of Genericity. Routledge, New York.

Heyer, Gerhard: 1990, 'Semantics and Knowledge Representation in the Analysis of Generic Descriptions', Journal of Semantics 7, 93-110.

Krifka, Manfred: 2004, 'Bare NPs: Kind-referring, Indefinites, Both, or Neither?', in O. Bonami and P. C. Hofherr (eds.), Empirical Issues in Formal Syntax and Semantics, Vol. 5, 111-132.

Krifka, Manfred, Francis J. Pelletier, Greg Carlson, Alice ter Meulen, Godehard Link, and Gennaro Chierchia: 1995, 'Genericity: an Introduction', in Carlson and Pelletier (1995), 1-124.

Longobardi, Guiseppe: 2001, 'How Comparative is Semantics? A Unified Parametric Theory of Bare Nouns and Proper Names', Natural Language Semantics 9, 335-369.

McNally, Louise: 1998, 'Stativity and Theticity', in S. Rothstein (ed.), Events and Grammar, 293-307. Kluwer, Dordrecht.

McNally, Louise: 2004, 'Bare Plurals in Spanish are Interpreted as Properties', Catalan Journal of Linguistics 3, 115-133.

Nunberg, Geoffrey: 1995, 'Transfers of Meaning', Journal of Semantics 12.

Palma, Helena L.: to appear, 'Plural Indefinite Descriptions with unos and the Interpretation of Number', Probus.

Partee, Barbara H.: 1987, 'Noun Phrase Interpretation and Type-Shifting Principles', in J. Groenendijk, D. de Jongh, and M. Stokhof (eds.), Studies in Discourse Representation Theory and the Theory of Generalized Quantifiers, 115-143. Foris, Dordrecht.

Partee, Barbara H. and Mats Rooth: 1983, 'Generalized Conjunctiom and Type Ambiguity’, in R. Bäuerle, C. Schwarze, and A. von Stechow (eds.), Meaning, Use, and interpretation of Language, 361-383. de Gruyter, Berlin.

Reinhart, Tanya: 1981, 'Pragmatics and Linguistics: An Analysis of Sentence Topics', Philosophica 27, 53-94.

Robinson, Heather: 2005, Unexpected (In)definiteness: Romance Plural Determiners in Generic Contexts, Doctoral Dissertation, Rutgers University.

Schubert, Lenhart K. and Francis J. Pelletier: 1987, 'Problems in the Representation of the Logical Form of Generics, Plurals, and Mass Nouns', in E. LePore (ed.), New Directions in Semantics, 385-451. Academic Press, London.

de Swart, Henriette: 1996, '(In)definites and Genericity', in M. Kanazawa, C. Piñon, and H. de Swart (eds.), Quantifiers, Deduction and Context. Center for the Study of Language and Information, Stanford. 
Van Geenhoven, Veerle: 1996, Semantic Incorporation and Indefinite Descriptions, Doctoral Dissertation, University of Tübingen. Published by CSLI, 1998. 